\title{
Spinal cord injury: 10 and 15 years after
}

\section{A Cushman PhD, J Hassett}

University of Rochester School of Medicine and Dentistry Rochester, New York 14642, USA.

\begin{abstract}
Researchers have only recently begun to study the problems and adaptations of persons who have lived with spinal cord injury (SCI) for many years. This descriptive study examined recent functional changes and perceptions regarding the quality of life in $43 \mathrm{SCI}$ persons who were 10 or 15 years post injury; 31 percent of the 137 persons surveyed (by mail) responded. On a general rating of quality of life, neither level nor completeness of injury was a significant factor. Subjects who were in a preferred current living situation had a significantly better perceived quality of life $(t=-3.2, p<.01)$; employment did not similarly affect quality of life ratings. There was no significant Spearman correlation between quality of life and the number of recent changes experienced in daily functioning $\left(r_{\mathrm{S}}=.17\right)$; likewise, quality of life was not related to involvement in exercise or other recreational activities. The nature of the changes most often experienced, as well as factors that persons saw as helping to maintain their independence, are described.
\end{abstract}

Keywords: spinal cord injury; quality of life; outcome assessment.

The lives of persons with spinal cord injury (SCI) many years after injury is littleexplored research territory, most often described only through anecdotal reports. Because of the inherent difficulties in doing longitudinal research, as well as the relatively recent development of specialized rehabilitation programs for SCI and more normal life expectancy for persons with SCI, information on long term outcome is indeed limited, particularly with respect to issues of quality of life.

A closely related area, one that was also virtually ignored until the last few years, is that of aging and SCI. This has been most closely examined by Trieschmann; ${ }^{1}$ however, much data remains to be collected. One theme that has emerged from this literature is that of possible changes in function due to many years of extraordinary effort from, for example, nonimpaired upper extremity joints and limbs in wheelchair propulsion. Anecdotal suggestions of accelerated aging in persons with SCI have

Correspondence: University of Rochester Medical Centre, Rehabilitation Unit, Box 664, 601 Elmwood Avenue, Rochester, NY 14642, USA. caused new-found attention to be given to this area.

Data on the long term psychosocial adjustment of persons with SCI are also sparse. Despite the longstanding perception that major adjustment problems were commonplace, careful studies ${ }^{2.3}$ have found that only a small percentage of newly injured persons have major depressive reactions or other significant coping problems, and there is also evidence that even early indications of coping difficulties subside substantially a few years after injury. Cook ${ }^{4}$ has shown that the overwhelming majority of SCI persons studied at 5 years post injury were functioning comparably to uninjured community residents in terms of life satisfaction and self perceived adjustment. Cook $^{4}$ also found that a third of the subjects he studied considered themselves to be, at 5 years post injury, closer to an ideal life than they had been prior to injury. Siosteen et $a l^{5}$ thoroughly reviewed activities, subjective quality of life, and mood in SCI persons who were an average of 2.8 years post injury. They found that quality of life was not related to severity of disability, whereas quality of life and mood were positively 
associated with increased social activities and independence in driving a car. However, the study was conducted in a society in which many more environmental and financial resources are typically available to SCI persons than in the United States; therefore, the relative influence of environmental factors and subjects' ability to participate in social and recreational activities may well have been different than in other studies. A recent study by Crewe and Krause $^{6}$ revealed an overall modest increase in self rated adjustment in an 11-year longitudinal follow up, as well as an increase in the proportion of the sample who were employed and who were married. In general, however, data on the proportion of persons with SCI who reach and maintain an optimal outcome, in terms of adjustment and other indicators of quality of life, and the factors that may influence this are yet to be collected. Efforts aimed at intervention during rehabilitation would be well served by data indicating what factors act as pivotal points for later adjustment, and for which persons.

The present study was an attempt to document, for a single SCI center, the current living situation and subjective quality of life reported by those persons with SCI who had completed their course of inpatient rehabilitation 10 and 15 years previously. It was thought that this would allow information to be gathered on a group of persons who would have had both many years of experience in adapting to SCI, and who might also now be entering middle age with possible age related changes in functioning. To gather the largest amount of information most efficiently, a single questionnaire, which included a global rating of quality of life, was compiled.

\section{Method}

\section{Subjects}

Subjects in the study were 43 persons (of a possible sample of 139) with spinal cord injury who had been injured $10(n=25)$ or $15(n=18)$ years previously and completed a stay on a local inpatient rehabilitation unit at that time. Subjects were those 43 persons who responded to the mailed questionnaire.
Subjects' current mean age was 47.6 years; their mean age at injury was 34.2 (Table I). Subjects' sex, type of injury, marital status and employment status are described in Table I. Known characteristics of non respondents are also listed in Table I.

\section{Procedure}

From records kept by the rehabilitation medicine division, the names of persons with spinal cord injury who had been injured either 10 years (January to December, 1978) or 15 years (January to December, 1973) prior to 1988 were compiled; there were 170 such persons. Thirty-one persons were known to be deceased. The remaining 139 persons were those we attempted to contact, by mail, to participate in the research project by completing an attached questionnaire; 43 persons responded (approximately $31 \%)$. Of those $(n=96)$ who did not

Table I Descriptive data for SCI persons who did and did not reply to the 10 or 15 year follow up questionnaire

\begin{tabular}{|c|c|c|c|c|}
\hline & $\begin{array}{l}\text { Respo } \\
\quad(n=\end{array}$ & $\begin{array}{l}\text { ndents } \\
=43 \text { ) }\end{array}$ & $\begin{array}{r}\Gamma \\
\operatorname{respc} \\
(n\end{array}$ & $\begin{array}{l}\text { on } \\
\text { ndents } \\
=96)\end{array}$ \\
\hline Age at injury & & & & \\
\hline Mean (SD) & $\begin{array}{c}34.2 \\
n\end{array}$ & $\begin{array}{c}(16.2) \\
\%\end{array}$ & $\begin{array}{c}34.17 \\
n\end{array}$ & $\begin{array}{c}(16.19) \\
\%\end{array}$ \\
\hline Sex & & & & \\
\hline Male & 31 & 72 & 71 & 74 \\
\hline Female & 12 & 28 & 25 & 26 \\
\hline Diagnosis & & & & \\
\hline Paraplegic & & & & \\
\hline complete & 16 & 37 & 40 & 42 \\
\hline incomplete & 8 & 19 & 18 & 19 \\
\hline Quadriplegic & & & & \\
\hline complete & 10 & 23 & 26 & 27 \\
\hline incomplete & 9 & 21 & 12 & 13 \\
\hline Marital status & & & & \\
\hline Married & 11 & 26 & - & \\
\hline Single & 21 & 49 & - & \\
\hline Divorced & 6 & 14 & - & \\
\hline Widowed & 3 & 7 & - & \\
\hline $\begin{array}{l}\text { Currently employed } \\
\text { Full time }\end{array}$ & 19 & 44 & - & \\
\hline Homemaker status & 26 & 68 & - & \\
\hline
\end{tabular}

Note: Data concerning marital status and employment was available only for study respondents. 
respond, $33(34 \%)$ were lost to follow up (with no current address or phone number available); the remainder presumably chose not to respond. Subjects who did not respond were not significantly different from respondents in terms of age $(z=1.50$, $p>.05)$ or in terms of the percentage with cervical injuries $(z=.44, p>.05)$ or incomplete injuries $(z=1.01, p>.05)$ (Table I).

The questionnaire addressed subjects' lesion (level and type), current living situation (where, with whom, and whether this was considered preferred), marital status, education, and employment (plus whether there had been any changes in the latter 4 since discharge). With respect to education and employment, subjects were asked if they had been to school or been employed at any time since injury, had sought either, and whether they were currently employed or in school. The questionnaire asked whether subjects were currently driving, regularly engaged in recreation or any exercise program, or needed any physical assistance for ADLs or mobility. Subjects were asked if they had experienced any of 9 changes potentially related to aging. The questionnaire also addressed subjects' perception of subjective quality of life. A global rating of quality of life was chosen, in which subjects were asked to rate their current quality of life relative to that of same age peers; the latter was rated on a 5-point scale with 1 being 'much better' than peers and 5 being 'much worse'.

\section{Results}

Current living situation compared with time of discharge

When asked if they were in a different living situation than arranged at discharge from the rehabilitation unit, 16 subjects $(40 \%)$ replied that there had not been a change in living situation. Of those who had such a change, 8 had been living with their parents and were now in an independent living situation. Changes in marital situation (6 persons got married, 2 divorced) accounted for another 8 changes in living situation. Seventy-four percent of subjects were living with a spouse or with family; $16 \%$ were living alone; $7 \%$ were living with a roommate; only $2 \%$ ( 1 person) was living in an institution. When asked if their current living situation was one that they preferred, $37(85 \%)$ subjects said 'yes'; 6 subjects $(15 \%)$ said their current situation was not their preferred living situation.

Upon discharge from the rehabilitation unit, $49 \%$ (21) of those surveyed were married; $26 \%$ (11) were single; $14 \%$ (6) were divorced and 7\% (3) were widowed. Marital status was not known for 5\% (2). At the time of our survey, $51 \%$ were unchanged; $16 \%$ had changed from single to married; $12 \%$ who had been married were divorced; $2 \%$ who had been divorced were married; $7 \%$ were widowed and $12 \%$ were unknown (ie did not respond to this question).

Nineteen $(44 \%)$ of the 43 persons in the study were currently employed. Six (31\%) of these 19 persons had not attended school after rehabilitation; the remainder had. Nineteen out of 43 persons (44\%) had attended school since their discharge from rehabilitation; 12 of these $19(63 \%)$ were also presently employed.

\section{Perceived quality of life}

The data on subjects' perceived quality of life was examined with respect to various injury and demographic variables. Most subjects saw their life as comparable to or somewhat better than that of same age peers (the mean score reported was 2.84 on a scale of 1 to 5). Quality of life ratings did not vary by subjects' level (thoracolumbar versus cervical) or completeness of injury (Table II). Subjects' perceived quality of life did not differ according to time since injury or current employment. However, subjects' living situation did $(t=3.20, p<.001)$. The latter measure reflected whether or not subjects viewed themselves as living in their most preferred setting, whether that be with family, alone, etc. (Subjects' views on the physical suitability of their dwellings were not addressed in this questionnaire).

To examine this more closely, subjects who rated themselves as having an overall quality of life 'somewhat' or 'much' worse than their peers $(n=13)$ were compared 
Table II Relationship of perceived quality of life to level and completeness of injury

\begin{tabular}{llc} 
& \multicolumn{2}{c}{ Quality of life } \\
\hline Level of injury & Mean & $t$ \\
$\quad$ Quadriplegia & 2.95 & $-0.60 \mathrm{~ns}$ \\
$\quad$ Paraplegia & 2.72 & \\
Completeness of injury & 2.65 & \\
$\quad$ Complete & & $-.80 \mathrm{~ns}$ \\
Incomplete & 3.00 & \\
\hline
\end{tabular}

Note: Lower numbers reflect better perceived quality of life.

with the remaining subjects $(n=30)$, who reported their quality of life as the 'same' or better than their peers. There were no differences in the percentage of subjects in each of these 2 groups with respect to level or type of lesion, sex, or marital status.

There were no differences in the proportion of subjects in each group who had returned or gone to school since completing their initial rehabilitation. The group with lower self reported quality of life had lower rates of current employment, though this did not reach statistical significance. However, the group with poorer subjective quality of life did report significantly lower rates of ever having sought employment since injury (Table III).

There were significantly fewer subjects in the group with poorer subjective quality of

Table III Employment and living situation information for SCI subjects with high versus low ${ }^{\text {a }}$ subjective quality of life

\begin{tabular}{lccc}
\hline & \multicolumn{3}{c}{ Subjective quality of life } \\
\hline & Low & High & \\
& $(n=13)$ & $(n=30)$ & $z$ \\
Currently employed & $31 \%$ & $50 \%$ & 1.23 \\
$\begin{array}{l}\text { Have sought employ- } \\
\text { ment since injury }\end{array}$ & $31 \%$ & $62 \%$ & $2.21^{*}$ \\
$\begin{array}{l}\text { Currently in a } \\
\text { 'preferred' living } \\
\text { situation }\end{array}$ & $58 \%$ & $96 \%$ & $2.62^{* *}$ \\
\hline
\end{tabular}

a'low' refers to below average, and 'high' refers to average or better than peers. ${ }^{*} p<.05$, ${ }^{* *} p<.01$ life who reported being in a 'preferred' living situation (Table III). However, the actual living situations of subjects in each group were not much different (Table IV). One subject in the group with low life satisfaction was institutionalized, but this could not have accounted for the (approximately) remaining one third of this group who claimed not to be living in their preferred setting.

There were no significant differences between the groups in terms of involvement in regular exercise or recreation, need for physical assistance in activities of daily living, or whether subjects currently drove. The groups also did not differ in terms of the number of age associated changes (from a possible list of 9) they reported.

\section{Age related changes}

Functional improvement since discharge was not a variable which we could reliably measure through a mail survey. Also, for the first years included in the survey, records could not be located which indicated functional ability at discharge. Nonetheless, we decided to use self reported functional changes occurring in the last 5 years to indicate possible effects of aging. Ninetythree percent $(n=40)$ of those surveyed indicated at least one change (see Table V) which has been described as associated with aging in persons with spinal cord injury. ${ }^{1}$

Questions addressing activity patterns and life changes (during the past 5 years) were next examined with respect to perceived quality of life. The quality of life measure did not vary according to whether or not subjects engaged in a regular exercise

Table IV Subjects' current living situation by rating of subjective quality of life

\begin{tabular}{llrrr}
\hline Living situation & \multicolumn{3}{c}{ Subjective quality of life } \\
\hline & \multicolumn{2}{c}{ Low } & \multicolumn{2}{c}{ High } \\
& $n$ & $\%$ & $n$ & $\%$ \\
Alone & 2 & 15.4 & 5 & 16.7 \\
Roommate & 1 & 7.7 & 2 & 6.7 \\
Spouse/Family & 9 & 69.2 & 23 & 76.7 \\
Institution/Other & 1 & 7.7 & 0 & - \\
\hline
\end{tabular}

Note: Percentages were rounded to the nearest tenth. 
Table $\mathbf{V}$ Frequency with which subjects affirmed various life changes as having occurred in the past 5 years

\begin{tabular}{rrrrl}
$\begin{array}{l}\text { Subjects 10 years } \\
\text { post injury } \\
(n=25)\end{array}$ & \multicolumn{5}{c}{$\begin{array}{c}\text { Subjects 15 years } \\
\text { post injury } \\
(n=18)\end{array}$} \\
\cline { 1 - 3 }$n$ & $\%$ & $n$ & $\%$ & Life change \\
16 & 64 & 7 & 39 & Substantial weight gain (or loss) \\
5 & 20 & 11 & 61 & New onset of pain in hands, arms or shoulders \\
12 & 48 & 9 & 50 & Onset of new medical problems \\
3 & 12 & 4 & 22 & Use of a new style of transfer \\
7 & 28 & 6 & 33 & Use of new adaptive equipment \\
5 & 20 & 4 & 22 & Changing daily routine secondary to extreme fatigue \\
4 & 16 & 2 & 11 & Increased need for physical assistance in daily activities \\
6 & 24 & 4 & 22 & $\begin{array}{l}\text { Decreased frequency of social visits with family or friends } \\
\text { Attending fewer activities outside the home secondary }\end{array}$ \\
7 & 28 & 6 & 33 & to fatigue \\
\hline
\end{tabular}

program or other regular form of recreation. Similarly, the number of negative life changes subjects experienced was not highly correlated with perceived overall quality of life (Spearman $r=.17$ ). The most frequent life changes experienced by subjects are illustrated in Table $\mathrm{V}$. The number of changes reported did not vary according to completeness of the injury; however, subjects who were paraplegic reported more changes $(m=3.96)$ than did quadriplegic $(m=2.28)$ subjects $(t=-2.47, p<.05)$. There were no differences in the frequency of specific life changes between those subjects 10 versus 15 years post injury, nor in the total number of changes between these 2 groups.

Subjects' participation in a regular exercise program was examined with respect to selected life change variables. No significant relationship was found between exercise and weight stability, or (inversely) with an increasing need for daily physical assistance. However, subjects who engaged in a regular exercise program were less likely to say they had changed their daily routine (in the last 5 years) due to fatigue (chi square $=7.04$, $p<.01)$.

Subjects' descriptions of those factors they thought had most helped maintain or increase their independence in the years since injury are found in Table VI. When asked to list any factors that had impeded their achievement or maintenance of independence, subjects reported the following factors: lack of motor return, weight gain, getting more tired and stiff ('getting old'), increased muscle and joint pain, another fall, and difficulty obtaining health insurance. Thus, of the limiting factors listed, three were very similar to ones listed as possible age associated changes.

\section{Discussion}

The persons with SCI who were surveyed 10 and 15 years post injury rated their perceived quality of life as equal to or somewhat better than that of their peers, on average. In this study, the quality of life measure used was chosen over disability or handicap rating scales in order to focus on persons' subjective perceptions. As has been found in other studies, ${ }^{5,7}$ the level and completeness of the injury did not appear to significantly alter adjustment or perceived quality of life.

The single factor that did seem related to life satisfaction was the ability of subjects to live in their preferred setting, with family members or otherwise. No other factor in the survey, including changes related to aging, was found to be related to perceived quality of life. This finding appears consistent with the work of Siosteen ${ }^{5}$ and Brown ${ }^{8}$ which showed that SCI persons with adequate resources had lives as fulfilling as those of a matched group of nondisabled persons. It would be interesting to further 
Table VI Subjects' description of factors that have helped to increase or maintain their independence since discharge from rehabilitation. (Categories were added at the time data were reviewed)

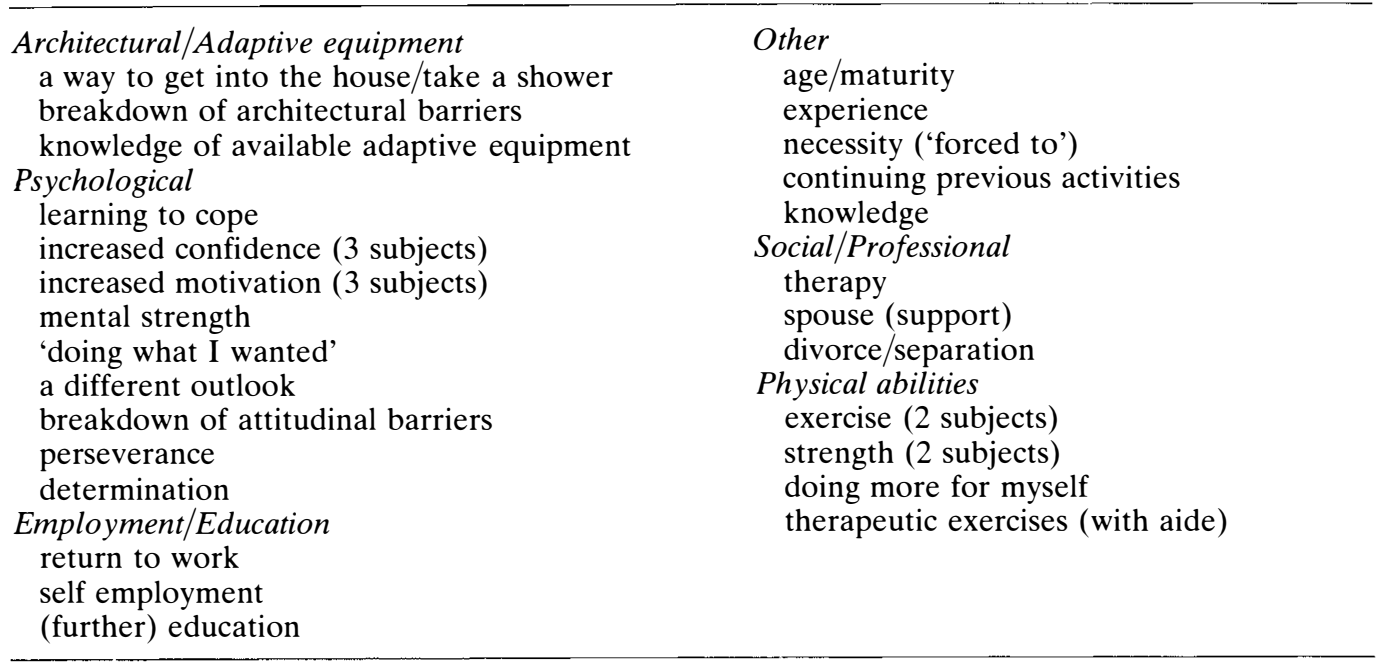

explore the role of facilitating independent (if desired) or other living situations in the overall satisfaction and adjustment of persons many years post SCI. However, the present study also indicates that it is subjects' perceived satisfaction (and presumed good 'fit') with their living situation, and not the type of social circumstance per se, that is most important. The large percentage of subjects with low subjective quality of life who reported not living in a preferred living situation may reflect the role of social perception and other, unexamined social factors, as their actual circumstances were not demonstrably different from those subjects who reported an average (or better) quality of life.

Subjects who were 15 years post injury did not show more changes in function than those 10 years post injury. Subjects who were paraplegic reported a greater number of negative changes than those who were quadriplegic. The latter may be related to a variety of possible 'overuse' syndromes as seen in a group who were presumably more functionally active on a daily basis. Those subjects who exercised regularly did not report significantly fewer problems with weight gain or a need for additional physical assistance. However, those who exercised regularly did report having to make fewer changes in their daily routine due to fatigue; this may parallel the overall health benefits seen in athletic versus nonathletic SCI persons described by Stotts. ${ }^{9}$ Obviously, fatigue is a highly subjective concept and may reflect a variety of mood based or physically based phenomena. Nonetheless our results suggest investigations of exercise programs designed to moderate the effects of fatigue that are presumed to be due to aging in persons post SCI would be a worthwhile effort. ${ }^{1}$

The factors that subjects listed as promoting independence were notable for their variety as well as the frequency with which psychological factors (eg attitude, motivation) were named. In fact, there were more instances of psychological factors as promoting independence than any other category identified. Further information on the development of such psychological resources over time since injury would likely prove informative, especially as to how they might be fostered by specific intervention.

Like other investigations of persons many years post SCI, this study has several limitations. Our sample had a higher mean age than the national average ${ }^{10}$ at the time of injury (34.2 years versus 29.7), as well as somewhat fewer males $(72 \%$ versus $82 \%)$, but was thought to be reasonably represen- 
tative nonetheless. The study suffers from the inherent limitations of being a cross-sectional versus a longitudinal study as well. The sample size was relatively small, and generalization may be limited by subjects' self selection in responding to the questionnaire. Although the non respondents were comparable to the study participants demographically and in terms of injury characteristics, their social situations and adaptation remain unknown. The psychometric properties of the questionnaire used to assess subjects' current activities and need for assistance had not been previously studied. Finally, the use of a global rating of quality of life may have yielded less information than other measures of the same construct.

In terms of future research, the obvious directions for expanding and strengthening a study such as this one would be to include more subjects, a longer follow up period, and to have more complete information, particularly with respect to psychosocial factors, at the time of SCI persons' initial rehabilitation. It would be interesting to know, for example, whether those things (eg premorbid coping strengths) that seem to predict favorable outcome over shorter periods also emerge as critical over a much longer interval. Further, it would seem important to know whether there are measurable individual differences that predict what types of assistance or intervention will prove most pivotal in fostering further independence and personal growth for a given individual. Perhaps even more important would be to delineate the ways in which various facilitating factors, especially psychosocial ones such as 'gaining confidence', are created, nurtured, and used by persons with SCI.

The broad band of interventions, from adaptive equipment to vocational training and participation in sports and recreation, used in rehabilitation settings for persons with SCI would seem to be supported by the present study. For different persons, a varying array of interventions seemed to help promote independence. In examining factors that were said to limit independence, some effects of aging did emerge. This suggests that late rehabilitative interventions, perhaps in the form of a clinic with an emphasis on such later onset problems as joint pain and decreased functional capacity, may play a useful role.

\section{References}

1 Trieschmann RB (1987) Aging with a Disability. Demos Publications, New York.

2 Carlson CE (1979) Conceptual style and life satisfaction following spinal cord injury. Arch Phys Med Rehabil 60: 346-52.

3 Macdonald MR, Nielson WR, Cameron MEP (1987) Depression and activity patterns for spinal cord injured persons living in the community. Arch Phys Med Rehabil 68: 339-343.

4 Cook DW (1982) Dimensions and correlates of postservice adjustment to spinal cord injury: A longitudinal inquiry. Int J Rehabil Res 5(3): 373-5.

5 Siosteen A, Lundqvist C, Blomstrand C, Sullivan L, Sullivan M (1990) The quality of life of three functional spinal cord injury subgroups in a Swedish community. Paraplegia 28: 476-488.

6 Crewe NM, Krause JS (1990) An eleven-year follow-up of adjustment to spinal cord injury. Rehabil Psychol 35: 205-210.

7 Kerr W, Thompson M (1972) Acceptance of disability of sudden onset in paraplegia. Int J Paraplegia 10: 94-102.

8 Brown M, Gordon WA, Ragnarsson KT (1987) Unhandicapping the disabled: What is possible? Arch Phys Med Rehabil 68: 206-9.

9 Stotts KM (1986) Health maintenance: Paraplegic athletes and nonathletes. Arch Phys Med Rehabil 67: 109-14.

10 Stover SL, Fine PR, editors (1986) Spinal Cord Injury: The Facts and Figures. University of Alabama Press, Birmingham, Alabama. 